ANNALES

UNIVERSITATIS MARIAE CURIE-SKŁODOWSKA

LUBLIN - POLONIA

VOL. LXX, 1

SECTIO AA

2015

\title{
Wetting properties of biosurfactant (rhamnolipid) with synthetic surfactants mixtures in the context of soil remediation
}

\author{
Elżbieta Hallmann* and Krystyna Mędrzycka \\ Gdańsk University of Technology, Chemical Faculty, \\ Narutowicza 11/12, 80-233 Gdańsk \\ *e-mail: elzbieta.hallmann@pg.gda.pl
}

Wetting properties of synthetic surfactant Rokanol NL6, biosurfactant JBR 425 and their mixture have been investigated. On the basis of these investigations, the ability of used surfactants to remove the synthetic base oil (PAO6) from sandy soil and clay loam was evaluated. Surfactant solutions were applied for soil flushing in batch experiments. The results show that synthetic surfactant addition worsens physicochemical properties of pure biosurfactant but exhibits much higher oil removal efficiency than biosurfactant does.

Keywords: biosurfactant, nonionic surfactant, surfactants mixtures, soil remediation.

\section{INTRODUCTION}

While soil pollution by petrochemical products is widespread and frequent, many remediation technologies have been proposed for treating oil contaminated sites [1]. Soil washing, one of the remediation methods, has drawn a lot of attention recently due to its little time consuming when compared with bioremediation or phytoremediation. Soil washing technique is suitable not only for hydrophobic substances removal but also can be applied to purification of soil contaminated by heavy metals [2]. As many 
common oil pollutants have low aqueous solubility and high interfacial tension at the oil/water interface, soil washing with water alone is ineffective. To overcome this inherent shortcoming, the addition of surfactant to flushing/washing solution is recommended [3].

Surfactants are markedly effective in enhancing the recovery of hydrophobic pollutants sorbed to soils when they are used at concentrations well above their CMC, due to solubilisation of contaminant inside the micelles. Surfactants can also mobilize residual non-aqueous phase liquids by reducing interfacial tension and this process takes place even when surfactant concentration is below the CMC.

Some of the synthetic surfactants used in soil remediation are hardly biodegradable and have a negative influence to the environment. For these reasons, in many areas of industrial applications including soil remediation, there is a tendency to substitute synthetic surfactants by more environmentally friendly natural surfactants. Biosurfactants become more and more popular in soil remediation applications. Biosurfactants, which are produced by a variety of microorganisms (also those, used in bioremediation), show better than synthetic surfactants environmental biodegradability and higher activity at extreme temperature, $\mathrm{pH}$ and salinity $[5,6]$. At the present time, biosurfactants are widely used with the great advantage of bioremediation processes [7]. Due to their physicochemical characteristics, like lower CMC value, more efficient solubilisation of hydrophobic substances [8], they are expected to be more effective in soil remediation than synthetic ones. On the other hand, nonionic surfactants are in the scope of interest in the majority of investigations as they are widely used in many applications $[9,10]$.

Though biosurfactants reveal favorable (for soil remediation) physicochemical properties and show good remediation results, using biosurfactants alone in the soil remediation processes is not economically reasonable as the cost of their production are still rather high. Therefore the idea to use biosurfactant and synthetic surfactant mixtures instead of biosurfactant alone can have more practical effects. The use of biosurfactant in soil flushing, even in small doses, would enhance bioremediation of residual oil and also would increase the biodegradability of surfactant composition. Physicochemical properties of surfactants like emulsification ability, surface tension lowering and wetting of soil particles, strongly affect the effectiveness of soil remediation processes. Thus, the objective of this research was to examine the possibility of soil remediation improvement by using the mixture of non-ionic surfactant and biosurfactant, instead of single 
surfactant solutions. The usefulness of these surfactants and their mixtures was evaluated basing on physicochemical measurements.

\section{EXPERIMENTAL}

\subsection{Materials}

Synthetic base oil, PAO6 (polyalfaolefine, Lotos S.A., Poland) was selected as hydrophobic pollutant. PAO6 is obtained by polymerization of 1-decene (for a viscosity of $6 \mathrm{~mm}^{2} / \mathrm{s}$ at $100^{\circ} \mathrm{C}$ ). Synthetic oils application have increased recently, however, these oils were never used in earlier carried out investigations on remediation. Surfactants used were JBR 425 (biosurfactant) and Rokanol NL6. Rokanol NL6 was obtained from PCC Rokita S.A. (Brzeg) and it is synthetic non-ionic surfactant, polydisperse mixture of polyethoxylated alcohols $\left(\mathrm{C}_{9-11} \mathrm{H}_{19-21}\left(\mathrm{OCH}_{2} \mathrm{CH}_{2}\right)_{6} \mathrm{OH}\right)$. Biosurfactant JBR 425 (Jeneil Biosurfactant Company, USA) is a 25\% aqueous solution of mono- and dirhamnolipids mixture. From the chemical point of view, rhamnolipids are glycosides of rhamnose (6-deoxymannose) and hydroxydecanoic acid, produced by the Pseudomonas bacteria. Surfactants were used as received from the suppliers without further purification. Selected physical and chemical properties of used surfactants are given in Table 1.

Table 1. Physicochemical properties of nonionic surfactant and biosurfactant used in investigations [11, 12].

\begin{tabular}{ccccc}
\hline Surfactant & Chemical structure & $\begin{array}{c}\text { Molecular } \\
\text { weight }\end{array}$ & $\mathrm{HLB}^{\mathrm{a}}$ & $\begin{array}{c}\mathrm{CMC} \\
{\left[\mathrm{g} / \mathrm{dm}^{3}\right]}\end{array}$ \\
\hline $\begin{array}{c}\text { Rokanol NL6 } \\
\text { (NL6) }\end{array}$ & $\mathrm{C}_{9-11} \mathrm{H}_{19-21}\left(\mathrm{OCH}_{2} \mathrm{CH}_{2}\right)_{6} \mathrm{OH}$ & 420 & 13.3 & 0.19 \\
& $\mathrm{C}_{26} \mathrm{H}_{48} \mathrm{O}_{9}\left(\mathrm{R}_{1}\right)$, & & & \\
JBR 425 & $\mathrm{C}_{32} \mathrm{H}_{58} \mathrm{O}_{13}\left(\mathrm{R}_{2}\right)$ & 576 & 24 & 0.07 \\
& $\mathrm{R}_{2}: \mathrm{R}_{1}=0.97: 1$ & & & \\
\hline
\end{tabular}

${ }^{\mathrm{a}} \mathrm{HLB}$ - Hydrophilic Lipophilic Balance.

Two sorts of soil samples were taken for investigations. As a model soil the sand was selected due to its uniform mineral composition, low 
particle porosity, and for its extremely low amount of fractional organic carbon. The sand was taken from the area localized in Gdańsk near LOTOS Refinery pipeline. As a second soil sample the clay loam was selected due to its high content of organic matter. The soil properties are shown in Table 2.

Table 2. Soil properties for soils used in this work.

\begin{tabular}{|c|c|c|c|}
\hline \multicolumn{2}{|l|}{ Item } & \multirow[b]{2}{*}{ Sand } & \multirow{2}{*}{ Clay loam } \\
\hline Soil texture & & & \\
\hline \multirow[t]{3}{*}{ Soil size fraction (\%) } & Sand & 95.23 & 41.2 \\
\hline & Silt & 4.77 & 23.5 \\
\hline & Clay & - & 35.3 \\
\hline $\mathrm{pH}$ & & 6.90 & 8.15 \\
\hline Organic matter (\%) & & 0.04 & 14.54 \\
\hline Water content $(\%)$ & & 0.01 & 31.61 \\
\hline
\end{tabular}

\subsection{Methods}

\subsubsection{Wetting properties}

The contact angle between soil and water described in Bachmann [13] was used in this study. The importance of surface roughness and chemical heterogeneity on wettability is obvious. Quantification of both effects is for heterogeneous soil particles basically impossible. A way out of this problem is to prepare quasi-smooth surfaces by limiting the heterogeneity of the grains. So, contact angle measurements were performed on a thin layer of the sieved soil fractions, which were fixed on an adhesive tape. To ensure a uniform and smooth surface, narrowly sieved particle-size fractions $(<100 \mu \mathrm{m}$, and $125 \div 150 \mu \mathrm{m})$ were used. The major reason for using sieved fractions was to obtain uniform surfaces, which should decrease heterogeneity of soil surface. A smooth microscope glass slide was covered with a double-sided adhesive tape. The dry soil was sprinkled on a 2- by $3-\mathrm{cm}$ area. Particles were pressed to the tape with a 100-g weight for 3 to $5 \mathrm{~s}$. The slide was then shaken carefully to remove surplus grains. This preparation technique was repeated twice for each sample. 
In order to compare the results of sand wetting with wetting the material of different hydrophobicity, plates made of glass and polytetrafluoroethylene (PTFE) were used. At least ten $2 \mathrm{~mm}^{3}$ drops were placed on the sample surface using a microsyringe. Contact angles were measured at room temperature $\left(23^{\circ} \mathrm{C}\right)$ using Krüss DSA 10 apparatus (Drop Shape Analysis System).

Wetting properties of RL solutions were investigated for glass, PTFE plates and for soil particles (two size fractions) attached to the plate. Investigations for RL/NL6 1:1 were made only for soil particles of $125 \div 150 \mu \mathrm{m}$ size fraction, attached to the plate.

\subsubsection{Soil washing in batch experiments (simulation of ex-situ method)}

The contaminated sand was prepared using a spiking method: $250 \mathrm{~g}$ of dried sand was mixed with $100 \mathrm{ml}$ of the spiking solution (7.5 g PAO6 oil in petroleum ether), so the initial oil content in the soil was about $30 \mathrm{~g} / \mathrm{kg}$. The contaminated sand was placed on the tray for 1 day to evaporate the ether. The investigations included soil washing by single component solutions as well as by mixture of biosurfactant and synthetic surfactant at 1:1 mass ratio of RL/NL6. In the case of single surfactants and mixtures of surfactants the total solution concentration was in the range of $0.5 \div 3 \mathrm{~g} / \mathrm{dm}^{3}$.

The washing tests were conducted in room temperature, $250 \mathrm{~g}$ of prepared oiled soil and $300 \mathrm{ml}$ of surfactant solution were placed in Erlenmeyer flasks and stirred at $300 \mathrm{rpm}$ using an IKA OST basic stirrer over 30 minutes. Stirring the content of the flask provided that washing of the oil from soil was conducted in dynamic conditions. After each washing process, the content of the flask was allowed to settle. The solution was decanted and the soil was rinsed with $100 \mathrm{~mL}$ of distilled water. The washed soil was dried and extracted with petroleum ether to determine the remained oil (not washed out during experiment). The solvent was rotary-evaporated and the amount of extracted oil was determined gravimetrically.

The experiments were duplicated and performed at ambient temperature $\left(23^{\circ} \mathrm{C}\right)$.

\section{RESULTS AND DISCUSSION}

Contact angle $(\Theta)$ of RL solutions on different surfaces are presented in Fig. 1 as a function of biosurfactant concentration. 
As it can be seen from Fig. 1 the wetting profile of RL solutions on all surfaces is a stepwise decreasing curve. At very low rhamnolipid concentrations (up to about $0.003 \mathrm{~g} / \mathrm{dm}^{3}$ ) the contact angle remained constant and equal to value for pure water. With further increase of surfactants concentration the contact angle decreases.

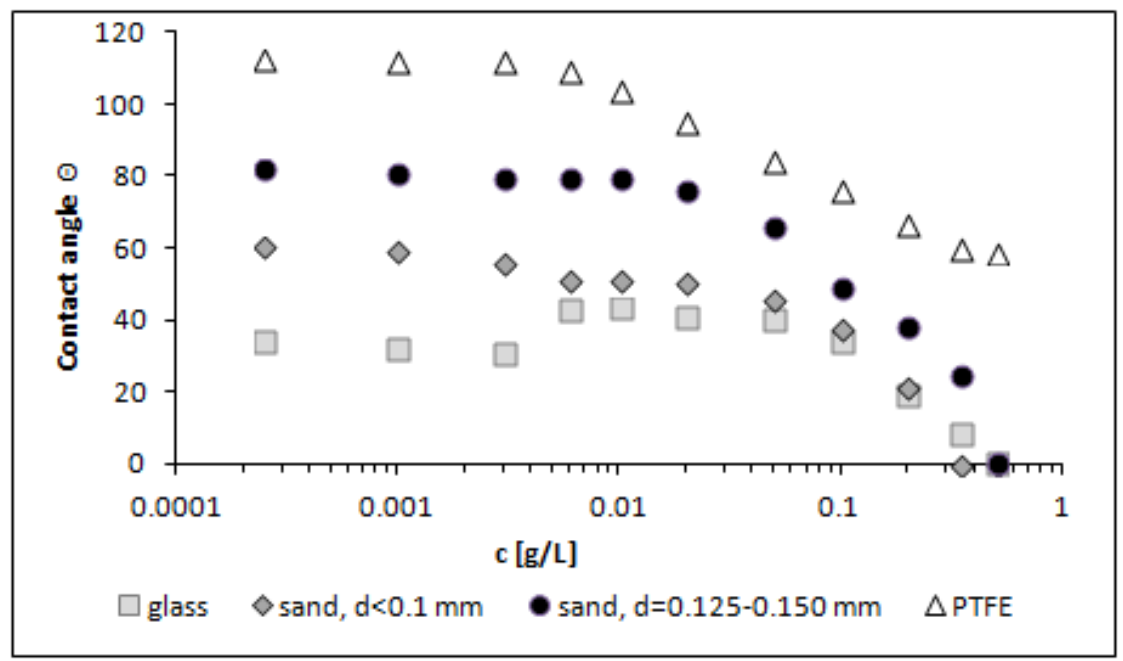

Fig. 1. Contact angles of RL solutions on different surfaces as a function of bulk concentration.

As it can be seen from Fig. 1 the wetting profile of RL solutions on all surfaces is a stepwise decreasing curve. At very low rhamnolipid concentrations (up to about $0.003 \mathrm{~g} / \mathrm{dm}^{3}$ ) the contact angle remained constant and equal to the value for pure water. With further increase of surfactants concentration the contact angle decreases.

Comparing the wetting of different surfaces one can see that $\Theta$ values are the highest on PTFE surface while on glass are the lowest. On the sand particles, contact angles have intermediate values. It is commonly known that glass and $\mathrm{SiO}_{2}$ surfaces have hydrophilic character while PTFE is rather hydrophobic. The contact angle profiles on the sand particles are more similar to that on glass, but shifted toward higher values. The higher the mean diameter of sand grains, the higher contact angle values were obtained. It is caused by surface heterogeneity, the combined impact of grain size, grain shape, microroughness, and particle size but not due to different surface properties of sand particles.

Glass surface is hydrophilic in nature and surfactant molecules are competing in adsorption with strongly adsorbing water molecules or they 
have to dehydrate first to be able to adsorb onto the surface [14]. Contact angle values increased to $40^{\circ}$ at $0.005 \mathrm{~g} / \mathrm{dm}^{3} \mathrm{RL}$ and remained again constant to $0.05 \mathrm{~g} / \mathrm{dm}^{3}$ RL concentration. With the increase of concentration, a gradual decrease in contact angle was observed until a complete wetting with $\Theta=0^{\circ}$ at $0.5 \mathrm{~g} / \mathrm{dm}^{3} \mathrm{RL}$ concentration.

Slightly different situation is in the case of PTFE hydrophobic surface. At low concentrations, surfactant molecules adsorb randomly in a horizontal configuration. With an increase in surfactant concentration they keep their horizontal configuration until a closed packed structure occurs and their tails begin to interact. A further increase in concentration causes a change in their orientation from horizontal to vertical [15]. Due to this behavior the contact angle of water $\left(111^{\circ}\right)$ remained almost constant up to biosurfactant concentration of $0.003 \mathrm{~g} / \mathrm{dm}^{3}$. At this concentration a closed packed structure of horizontally oriented rhamnolipids was obtained. With a further increase in the concentration, biosurfactant molecules rise up vertically with their tails adsorbed to the surface, causing a rapid hydrophilization of the surface, due to head groups extended into the solution. Accordingly to this behavior the contact angle is decreased to $59^{\circ}$ at RL concentration $0.5 \mathrm{~g} / \mathrm{dm}^{3}$.

Contact angle $(\Theta)$ results for solutions of NL6, RL and RL/NL6 composition of $1: 1$ are presented in Fig. 2 as a function of surfactant concentration. They relates only to sand particles $(d=125 \div 150 \mu \mathrm{m})$.

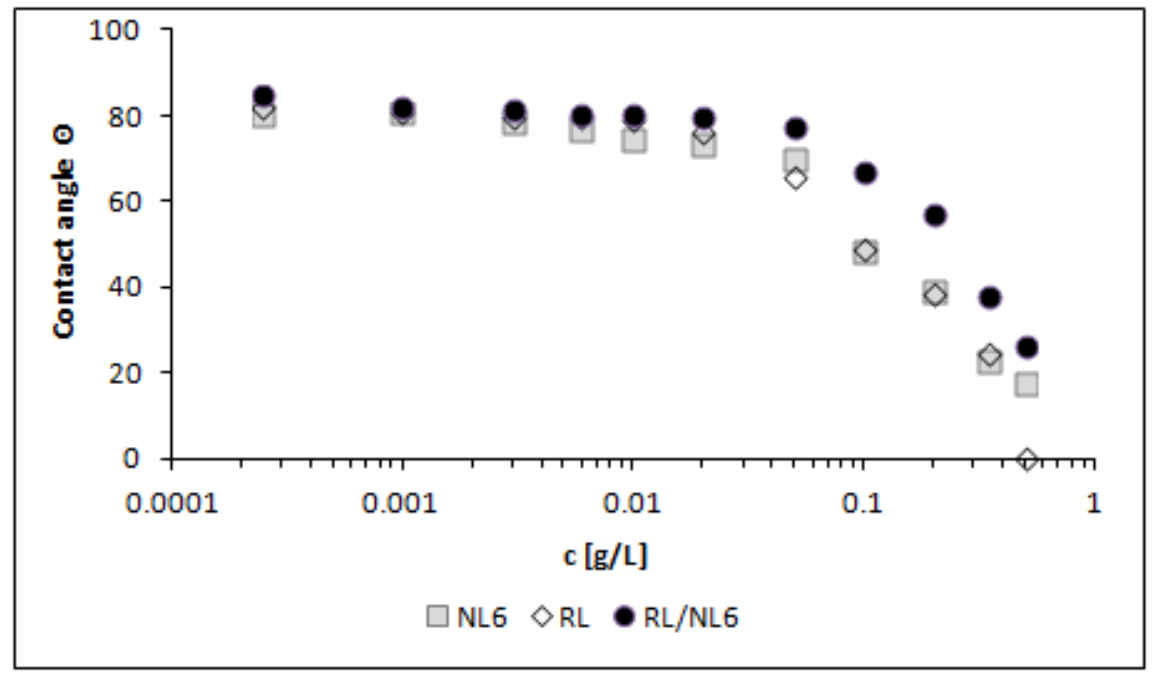

Fig. 2. Contact angles of NL6, RL and RL/NL6 composition of $1: 1$ on sand particles $(\mathrm{d}=125 \div 150 \mu \mathrm{m})$ as a function of surfactants bulk concentration. 
The wetting profiles of RL and NL6 solutions on the sand particles are very similar. At low concentration the contact angle remained almost constant. From concentration $0.02 \mathrm{~g} / \mathrm{dm}^{3}$ of $\mathrm{RL}$, a gradual decrease in contact angle was observed to the $\Theta$ value of $0^{\circ}$ at $0.5 \mathrm{~g} / \mathrm{dm}^{3} \mathrm{RL}$ concentration (Fig. 2).

A similar behavior was observed for contact angles of surfactants mixture. At low concentrations, the contact angle $85^{\circ}$ remained almost constant until a bulk concentration reaches $0.02 \mathrm{~g} / \mathrm{dm}^{3}$. Analyzing the results one can say that at low concentrations pure biosurfactant and the mixture had similar wetting properties. However, at higher concentrations biosurfactant had slightly better wetting properties of sand particles than RL/NL6 mixture.

Rhamnolipid was examined for its efficiencies in PAO6 oil removal from contaminated soils (Fig. 3). RL solution, $\left(0.5 \mathrm{~g} / \mathrm{dm}^{3}\right)$, removed $44 \%$ and $63.5 \%$ of oil from clay loam and sandy soil, respectively. Increase in surfactant concentration led to more PAO6 removal from sandy soil, and at RL concentration $2 \mathrm{~g} / \mathrm{dm}^{3}$ it was $97 \%$. While in the case of clay loam soil, the increase of surfactant concentration did not enhance oil removal (Fig. 3). Organic matter associated with clay, gives soil greater hydrophobicity, which cause greater adsorption of organic pollutants on clay loam than on sandy soil. Probably, PAO6 oil was strongly adsorbed to clay loam soil and washing it out by RL solutions was ineffective.

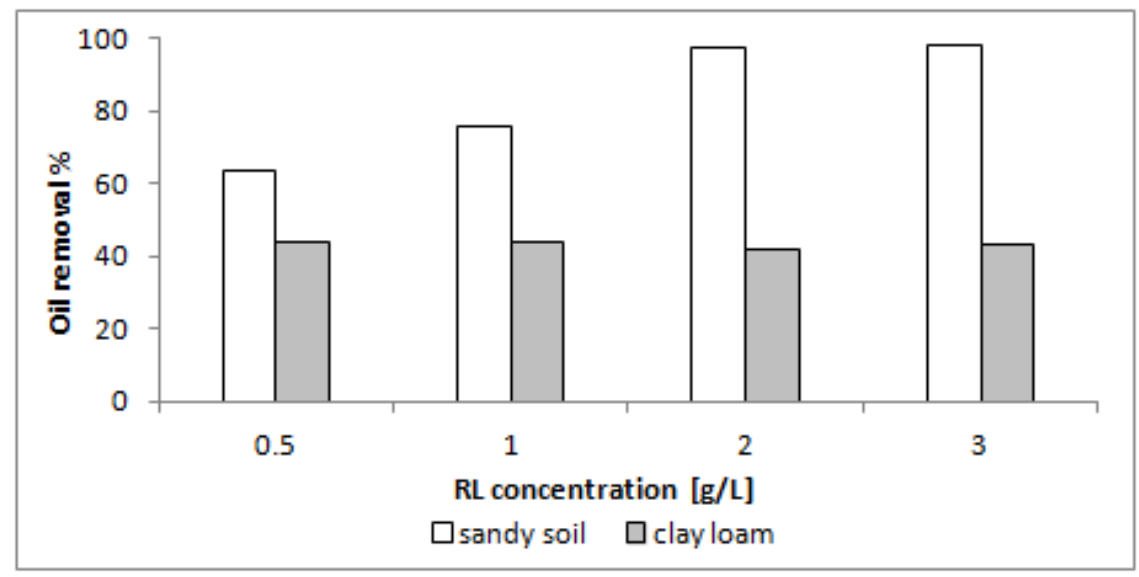

Fig. 3. Effect of RL concentration on PAO6 oil removal from sandy soil and clay loam.

Analysing the results presented in Fig. 4, one can state that synthetic surfactant treatment exhibited excellent PAO6 removal from soil, much 
better than in case of RL. It was about $62 \%$ and $92 \%$ from clay loam and sandy soil, respectively (Fig. 4). However, the addition of biosurfactant to NL6 (RL/NL6 1:1) leads to significant worsening in the oil removal efficiency for both, clay loam and sandy soil. On the other hand, mixture of biosurfactant with NL6 revealed greater oil removal from clay loam than from sandy soil, which was opposite to effectiveness when single components were used.

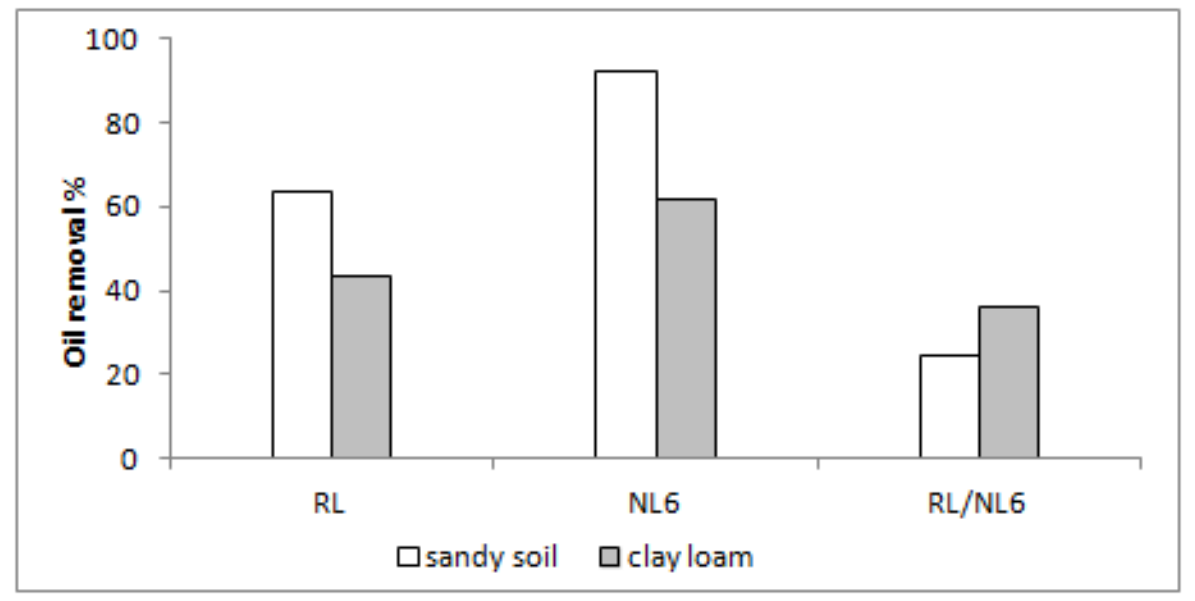

Fig. 4. Effect of the type of surfactant used on PAO6 oil removal from sandy soil and clay loam at total surfactants concentration $0.5 \mathrm{~g} / \mathrm{dm}^{3}$.

As the surfactant concentration in solution was increased all the surfactant solutions showed improved PAO6 oil removal from sandy soil. This trend was expected, as the force of attraction between soil and oil would be reduced due to the decrease in contact angle and change in wettability of the system in the presence of surfactants.

\section{CONCLUSIONS}

The removal of oil may be attributed to reduction of contact angle at oil/soil/air interface by surfactant solutions. This effect together with decreased interfacial tension contributes to the increase in the mobility of oil and consequently enhances its separation from soil due to the reduction of capillary forces holding the soil and oil together. Results presented in Figs. 1 and 2 are very promising when consider that the total 
wetting of sand particles was obtained at very low concentration $0.5 \mathrm{~g} / \mathrm{dm}^{3}$ of both, biosurfactant and biosurfactant with NL6 mixture.

The results of oil removal from clay loam and sand with solutions of surfactants mixture at concentration $0.5 \mathrm{~g} / \mathrm{dm}^{3}$ were comparable and ranged from 25 to $36 \%$. However, at higher concentrations of single component solutions, the oil was more easily removed from the sand (removal can even reach 99\%) than from the clay loam (40-60\%). This results from the difference in these soils composition. In the sand the main components are inorganic minerals, while the clay loam soil contains a large amount of organic matter. The differences in their composition cause different wetting of the soil grains by aqueous solution (better in case of more hydrophilic sand) and thus the different effects in oil removal.

Summarizing one can say that the addition of NL6 surfactant to the rhamnolipid solutions worsens the wetting properties of pure RL, while in soil washing tests this synthetic surfactant showed better than RL results in oil removal, especially in case of sandy soil.

\section{REFERENCES}

[1] D. F. Lowe, C. L. Oubre, C. H. Ward, Surfactants and Cosolvents for NAPL Remediation. A Technology Practices Manual, Lewis Publishers, 2000.

[2] S. Wang, C. N. Mulligan, Process Biochem., 44, 296-301, (2009).

[3] C. N. Mulligan, R. N. Yong, B. F. Gibbs, Eng. Geol., 60, 371, (2001).

[4] M. J. Rosen, Surfactants and Interfacial Phenomena, third ed., Wiley-Interscience, New Jersey, 2004.

[5] K. Muthusamy, S. Gopalakrishnan, T. K. Ravi, P. Sivachidambaram, Curr. Sci., 94, 736-747, (2008).

[6] M. Nitschke, S. G. V. A. O. Costa, J. Contiero, Biotechnol. Prog., 21, 1593-1600, (2005).

[7] R. Elliot, N. Singhal, S. Swift, Crit. Rev. Env. Sci. Technol., 41, 78-124, (2010).

[8] S. Pastewski, E. Hallmann, K. Mędrzycka, Environ. Eng. Sci., 23, 579-588, (2006).

[9] E. C. Butler, K. F. Hayes, Water Res., 32, 1345-1354, (1998).

[10] K. D. Pennell, A. M. Adinolfi, L. M. Abriola, M. S. Diallo, Environ. Sci. Technol., 31, 1382-1389, (1997). 
[11] PCC Rokita product data sheet, 2005.

[12] JBR product data sheet, 2004.

[13] J. Bachmann, A. Ellies, K. H. Hartge, J. Hydrol., 231-232, 66, (2000).

[14] E. A. Vogler, Adv. Coll. Interf. Sci., 74, 69-117, (1998).

[15] S. W. Musselman, S. Chander, Colloids Surf. A: Physicochem. Eng. Aspect, 206, 497-513, (2002). 